\title{
Specific Features of Friction Mechanisms of Thin- film Coatings of Parts of Mining Machines Working in Fretting Corrosion
}

\author{
Maksarov V.V. \\ Department of Mechanical Engineering \\ Saint-Petersburg Mining University \\ St. Petersburg, Russia \\ maks78.54@mail.ru
}

\author{
Krasnyy V.A. \\ Department of Mechanical Engineering \\ Saint-Petersburg Mining University \\ St. Petersburg, Russia \\ vikras1955@yandex.ru
}

\begin{abstract}
The paper consideres the occurrence of fretting corrosion on nominally fixed surfaces of highly loaded parts of mining machines and mechanisms. The authors give examples of wear and damage of critical parts operating under fretting. The mechanisms of fretting corrosion when using wear-resistant coatings were considered. It is noted that when selecting materials of protective coatings of parts, which are heavy-mates from fretting, it is necessary to pay attention not only to their durability, but also to the shear sensitivity. The use of sufficiently thin coatings, which are convenient because they do not violate the maintainability of components and allow one to save parts being in tension during the operation in the assembly. The results of studies of a number of wear-resistant coatings are presented to reduce wear under fretting in a special unit. The authors studied the wear mechanisms of a number of thin-film coatings based on mechanical friction-brass plating, fluorocarbon polymer composition and vibration knurling, using scanning electron microscopy techniques.
\end{abstract}

Keywords - wear-resistant coatings; fretting corrosion; mining machinery; vibration knurling.

\section{INTRODUCTION}

One of the vital tasks of general and mining engineering is to improve performance of machine parts. Such improvement is closely related to the choice of protective and antiwear coatings for work surfaces and the methods of secondary and finishing machining.

Various types of mining, transportation and refining equipment are used in mines and quarries at present; whereupon extra-heavy equipment operating under high loads and elevated vibrations is used over the last years. Not infrequently loads arising in the process of operation cause substantial wear of critical parts that in number of cases leads to extreme kinds of wear, such as scoring, gripping, jamming and fretting corrosion. The parts and subassemblies of mining machinery and equipment that are most vulnerable to such damage are: rolling bearings, sleeves, flanges, geared transmission, hinged joints, speed variators, splined and keyed connections, bolted and riveted joints, turbine blade locking pieces, ropes, valves and slide valves of hydraulic systems, pushrods of cam mechanisms, springs, as well as parts of heavily loaded subassemblies of internal combustion engines of open-pit dump trucks and locomotives [1].
A type of wear is fretting corrosion that manifests itself during vibration of nominally stationary parts when, because of minimum friction amplitude, wear products are not removed from the contact zone and render a significant influence on the wear mechanism $[2,3]$. Fretting corrosion is a frequent cause of breakdown of a number of critical parts of internal combustion engines, in particular, those of large openpit dump trucks, drilling equipment parts and other ones operating under vibration and high subgrade stresses. The development of fretting corrosion damaged is observed in large locomotive and marine diesels on the interfaces of the external surface of bearing linings with crankshaft bearing seats, as well as upon contact of the abutment surface of the master cylinder sleeve jacket with the abutment surface of its framework. Similar phenomena also took place at the interfaces of the side surfaces of main bearing caps and cylinder blocks of large open-pit trucks.

Fretting corrosion is a frequent cause of reduced reliability of a number of vital parts of machines, including mining machinery and mechanisms [4].

Machinery operation conditions are similar in the majority of ore mining and refining plants, they mainly differ in climatic and road conditions of rock mass transportation. Almost without exception, the routine of rock transportation is also the same, i.e. with load - uphill and without load downhill. A characteristic feature of the motor transport engine is its transient operation mode. During mining works, operation modes change 15-20 times during a trip; this amounts to approximately $30-40$ mode switchings per hour. A consequence of operation of diesel engines under overload is increased shifting, bending and twisting of mating parts, and first of all, main bearing caps and the cylinder block; such operation conditions result in emergence and development of fretting corrosion.

Numerous examples of fretting corrosion damage of various parts and subassemblies and methods of protection against fretting corrosion are described in the literature [5-7]. However, researchers did not arrive to a common conclusion as regards the mechanism of fretting corrosion and, respectively, the choice of measures aimed at its prevention.

Various types of coatings of working surfaces of machine parts are often used for preventing such kind of damage. 


\section{CHOICE OF WEAR RESISTANT COATING FOR PROTECTION OF PARTS AGAINST FRETTING CORROSION}

Three types of coatings are distinguished depending on the requirements imposed on the performance characteristics of parts: protective ones, used for protection of products against corrosion in various environments (in atmosphere, aggressive environments, etc.); protective-decorating ones, used for decorative finish of products with their simultaneous corrosion protection; special or functional ones - for imparting special properties (hardness, wear resistance, antifriction properties, etc.) to surfaces of products. The choice of type of coatings is determined by service conditions of the parts in question.

It is necessary to note differences in friction mechanisms during continuous friction and during fretting, friction with very small oscillations and under a dynamic load. The specific features of wear of surfaces under the conditions of fretting associated with small amplitude of nominally stationary joints are connected with retention of wear products in the contact zone. They play the role of a "third body" in operation and may both accelerate the process of wear because it goes along with corrosion processes and decelerate it.

Wear of surfaces under the conditions of fretting is characterized by the following peculiarities:

- sliding friction occurs under the conditions of reciprocating movement;

- fretting occurs in the air;

- when the set amplitude of sliding is achieved, the counterbody begins moving back.

- the counterbody is rigidly fixed in a clamp; it contacts with the surface continuously under a preset permanent load;

- in the process of friction, the counterbody increases its contact area with the coating;

- every patch of the coating friction surface is subjected to an intermittent-symmetric cycle of interaction with the counterbody;

- as the counterbody contact surface increases, the width of the coating friction area increases as well;

- wear products are only partially removed from the contact zone, they take an active part in the process of friction and wear.

During fretting wear, crystal lattice of surface layers works loose and disintegrates under the action of friction forces that manifest themselves in cyclic tangential displacements. The process of disintegration is essentially surface dispersion without removal of wear products.

Metal particles torn away from the friction surface and juvenile areas of that surface are quickly oxidized by air oxygen. Gripping that arises at some contact points of friction pairs may serve as an additional source of surface damage.

A simplified pattern of the process of fretting wear in its initial stage is as follows: displacement and deformation of surfaces under the action of fluctuating tangential stresses - oxidation - disintegration of oxide films - exposure of bare metal and gripping in places - disintegration of gripping spots and adsorption of oxygen by bare areas.

The mechanism of wear in the process of fretting is shown in Fig. 1 [3] in a simplified form. Initial contacts between parts occur at separate surface points (see Fig. 1,a). Under the impact of vibration oxide films in the zone of actual contact disintegrate, small caverns are filled with oxide films set in (Fig. 1,b). They gradually increase in size and merge into a single large cavern (Fig. 1,c). Pressure of oxidized metal particles in it increases; cracks form. Some cracks merge, and chipping of separate metal volumes occurs. Oxide particles act as an abrasive. As a result of action of high pressure and oxide particles, friction forces temperature increases, and white hard nonerodible structures form in the chipped particles and on the surface of caverns.
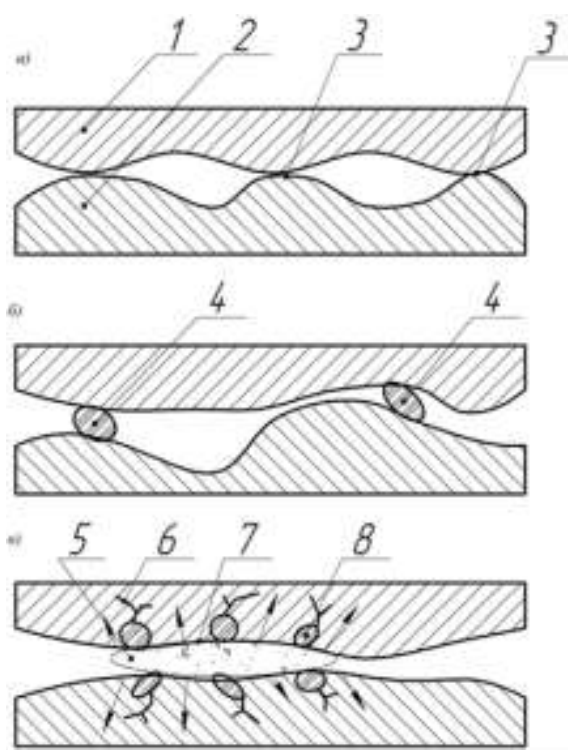

Fig. 1. Fretting wear mechanism:

1, 2 - contacting parts; 3 - surface contact points; 4 - small incipient caverns; 5 - common large cavern; 6 - cracks; 7 - chipped volumes of metal; 8 - chipped particles with a hard structure

When choosing materials for coatings protecting high-load joint parts from fretting corrosion, one should take into account not only their wear resistance, but also their shift sensitivity, i.e. the ability of a material to take shear deformation without initiating fatigue damage processes. It is known that it is a feature of sufficiently thin coatings. Those coatings have yet another advantage: they do not impede overhaulability of assemblies and permit to retain negative allowances specified during assembly in the process of operation $[3,5]$

In many cases, special kinds of processing, in particular, vibration knurling creating a regular microrelief on the surface prove to be effective in fretting control $[8,9]$.

The purpose of this work is to study the influence of coatings based on fluorocarbon polymer compound, friction mechanical brass plating, as well as surface vibration knurling forming a regular microrelief on the wear of high-load joints 
of mining machinery operating under fretting corrosion conditions.

\section{MATERIALS AND EXPERIMENT PROCEDURE}

Samples were tested according to the procedure on a special FK testing facility using the principle of a standard friction machine (Fig. 2). In all cases, coatings were applied to fixed samples and mobile countersamples were not coated.

The fixed sample (1) was a disk $35 \mathrm{~mm}$ in diameter and $7.5 \mathrm{~mm}$ thick. The moving countersample (2) was a hollow cylinder which internal and external diameters amounted, respectively, to 25 and $20 \mathrm{~mm}$. Its end (ring) surface contacted with the flat surface of the sample, creating a ring contact 0.5 $\mathrm{cm}^{2}$ in area. An eccentric (7) with eccentricity equal to $0.1 \mathrm{~mm}$ and a rocker arm (5) caused the cylinder to execute cyclic rotary oscillations around its own axis. Axial loads applied to it created preset pressures acting at right angle at the contact surfaces. This testing facility allowed one to vary fretting amplitude at contact surfaces from 40 to $200 \mu \mathrm{m}$, to change pressure applied at right angles from 10 to $50 \mathrm{MPa}$ and to create oscillation frequency from 200 to 1000 cycles per minute thanks to using a friction machine drive. An eccentric was used as the top roller in the standard "roller to roller" test procedure. This design allowed us to obtain reciprocating rotary oscillations of moving countersamples and to use measuring capabilities of the friction machine (friction moment and coefficient) [10].

Linear wear of samples was measured by processing friction track profile diagrams obtained on a standard profilograph-profilometer. Mass wear was assessed by weighing the samples on an electronic scale with $0.1 \mathrm{mg}$ precision before and after tests.

\section{TEST RESULTS AND THEIR DISCUSSION}

Initially, various kinds of coatings applied to steel and cast iron samples were tested to determine their comparative fretting wear resistance chcaracteristics under high contact loads. In Fig. 3, one can see the results of tests of steel samples $(3, a)$ and cast iron countersamples $(3, b)$, both ground and uncoated (1) and covered with various kinds of coatings: galvanic copper $(2,3)$ and bronze (4) plating of various thickness, friction mechanic brass plating (5), molybdenum deposition (6), uncoated vibration knurled samples (7), laserannealing in solid (8). Test conditions were as follows: standard pressure - $25 \mathrm{MPa}$, amplitude - $100 \mu \mathrm{m}$, frequency 900 cycles per minute; they imitated real conditions occurring during operation of heavy-duty components of mining machines. Number of test cycles $-5 \times 10^{5}$.
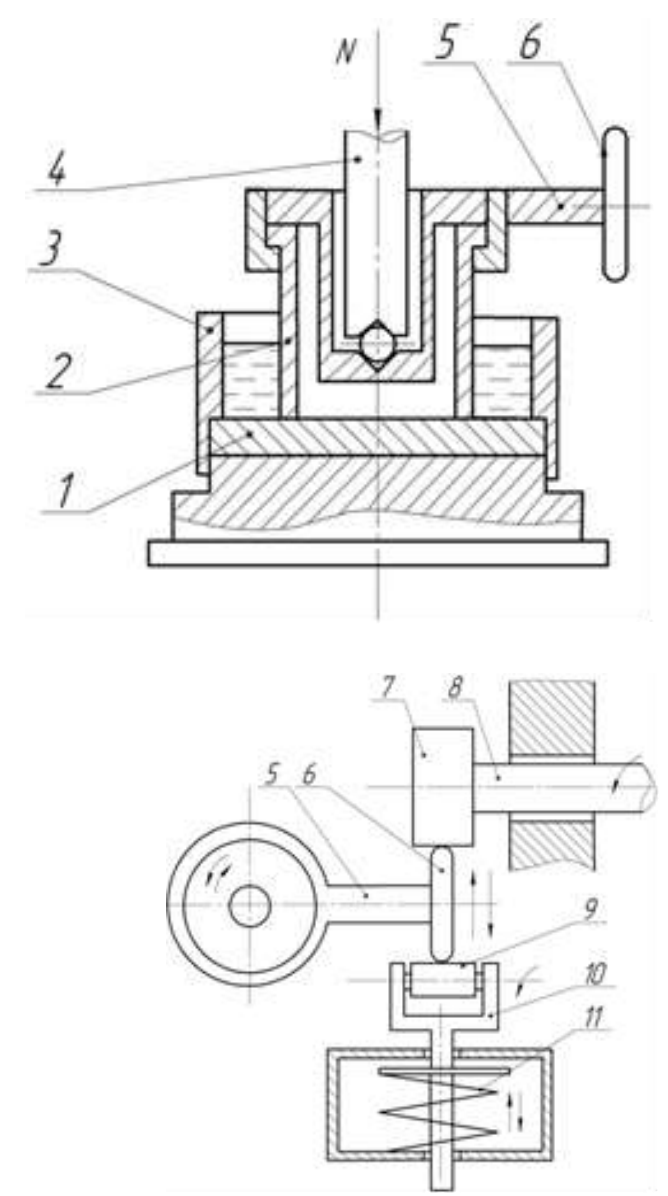

Fig. 2. Arrangement of FK Friction Machine: 1 - fixed sample, 2 - moving sample, 3 - liquid process medium cell, 4 - thrust rod, 5 - rocker arm, 6 roller, 7 - eccentric, 8 - drive shaft, 9 - pressure roller, 10 - fork, 11 - spring

The foregoing results demonstrate that thickness and hardness of coating are by no means always effective under the conditions of low-amplitude fretting when not only antifriction properties of a material, but its ability to resist lateral displacement and prevent fatigue damage processes play a substantial role.

Further tests studied fretting wear of model samples made of grade 15 steel and grade GG25 (DIN 1691) gray cast iron covered with coatings which utilization is expedient for large parts having complex shapes, when such traditionally used protection methods as electroplating or vacuum deposition of coatings, as well as laser annealing of part surfaces prove themselves as technologically inapplicable. The authors studied friction surfaces of samples after coating with polymer fluorocarbon compound and friction mechanical brass plating as compared to original samples without coatings and surface treatment. All kinds of coatings were applied to friction surfaces of stationary parts of friction couples. 


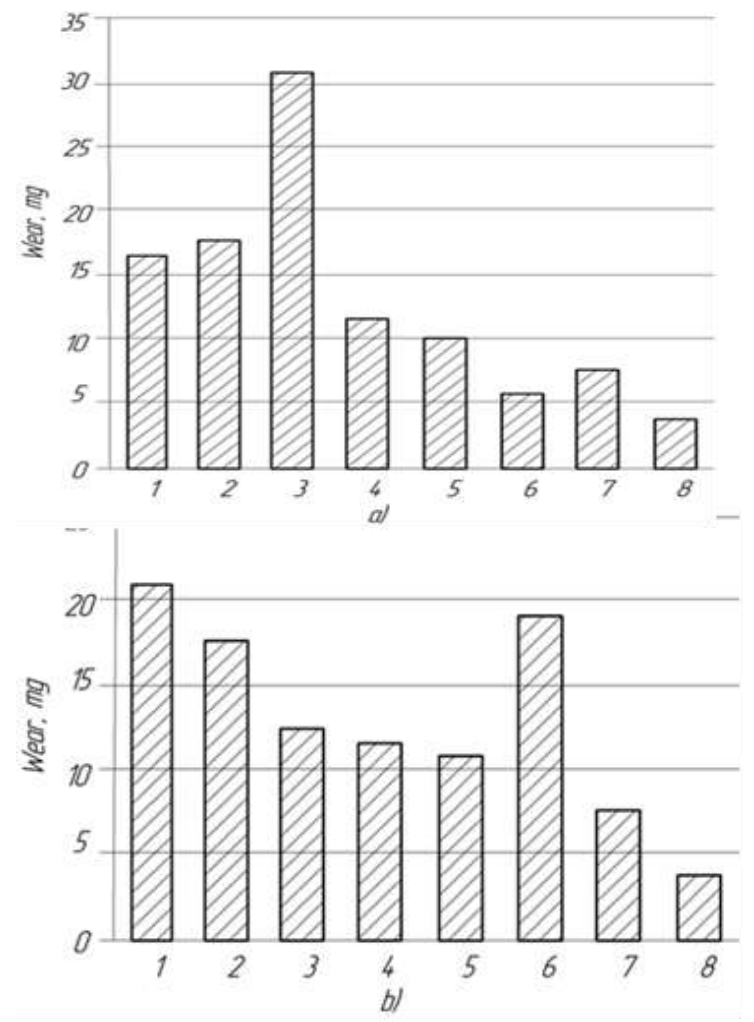

Fig. 3. Results of fretting wear tests: a) - wear of samples, mg; b - wear of countersamples, mg. Samples: 1 - uncoated; 2 - with galvanic copper plating $5 . .8 \mu \mathrm{m}$ thick; 3 - with galvanic copper plating $30 \mu \mathrm{m}$ thick; 4 - with electrolytic bronze plating $15 \mu \mathrm{m}$ thick; 5 - with friction mechanic brass plating 3...5 $\mu \mathrm{m}$ thick; 6 - samples with molybdenum deposition $0.2 \mathrm{~mm}$ thick; 7 - vibration knurling creating a regular microrelief; 8 - laser annealing in solid

The first series of samples and countersamples made of grade 15 steel were tested by rotating and reciprocating motion with $100 \mu \mathrm{m}$ amplitude under $25 \mathrm{MPa}$ pressure and at 900 cycles/min. frequency. The second series of tests was performed on samples made of GG25 (DIN 1691) grade cast iron and grade 15 steel counter-samples with $20 \mu \mathrm{m}$ displacement amplitude and at 250 cycles/min frequency under $50 \mathrm{MPa}$ pressure. The number of load cycles for each pair of samples amounted to $5 \times 10^{5}$, at least 4 samples with each type of coating have been tested. Wear after tests was assessed by mass change of the samples within the accuracy of $0.1 \mathrm{mg}$. Linear wear was assessed by friction tracks profile diagram.

Friction coefficient was determined by calibration graphs according to resistive strain gauge readings. The results of tests of the samples described above are shown in Fig. 4 in comparison with the uncoated samples data. In Fig. 4, a, one can see the results of fretting wear tests of metal samples (where $\mathrm{U}$ is linear wear, $\mu \mathrm{m} ; \mathrm{U}_{\mathrm{m}}$ is wear measured by a sample mass change, mg), in fig. $4, \mathrm{~b}$, the wear of countersamples, and in Fig. 4, c, the values of established friction coefficients $\mu$. Steel samples were used for tests Nos. 1-3 inclusive, whereupon No. 1 is an uncoated sample, No. 2 is a sample coated with 3-5 $\mu \mathrm{m}$ thick friction mechanical brass plating , No. 3 is a sample coated with $5 \mu \mathrm{m}$ thick fluorocarbon polymer compound. Samples Nos. 4-6 were made of cast iron, whereupon sample No. 4 was uncoated, sample No. 5 was coated with friction mechanical brass plating and sample No. 6 - with fluorocarbon polymer compound.
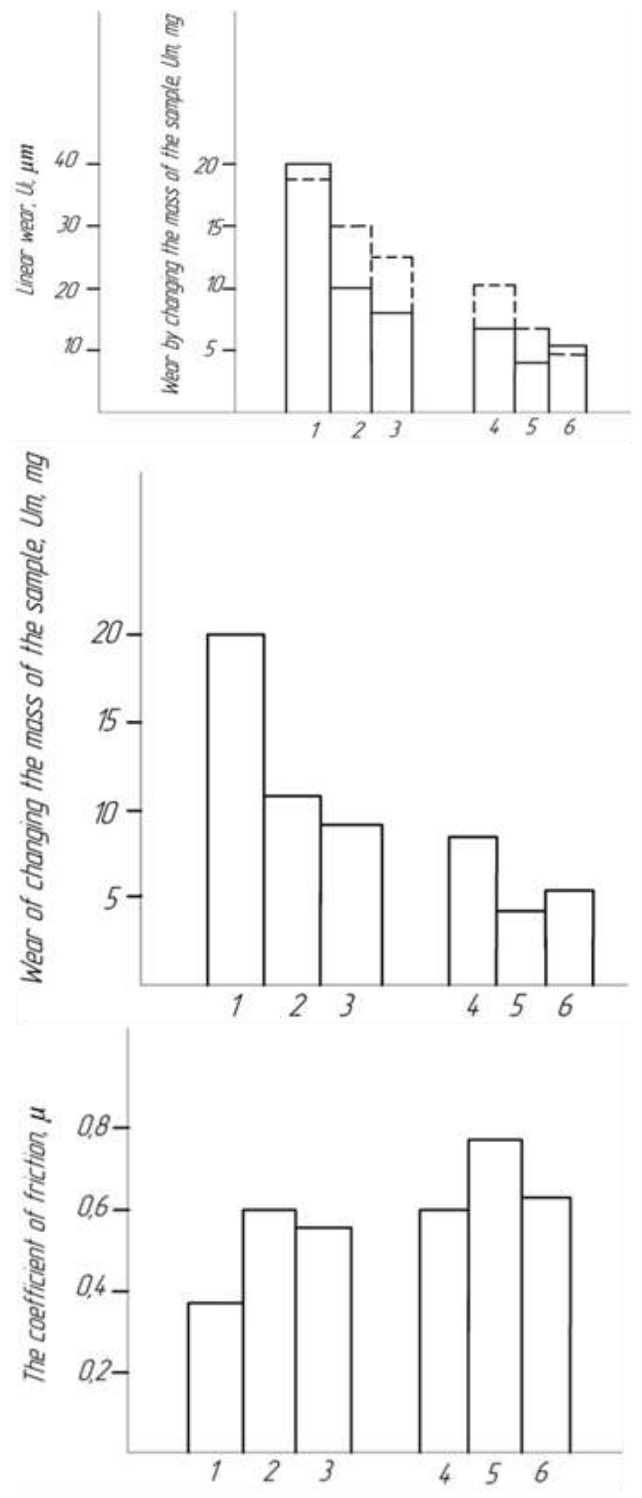

Fig. 4. Fretting test results: a) - wear of samples (contour line - mass wear, dashed line - linear wear); b - wear of countersamples; c) - values of established friction coefficient; (1 - 3 - steel samples: 1 - uncoated; 2 - friction mechanical brass plating, thickness $3 . .5 \mu \mathrm{m} ; 3$ - fluorocarbon polymer compound, thickness $5 \mu \mathrm{m} ; 46$ - cast iron samples: 4 - uncoated; 5 - friction mechanical brass plating; 6 - fluorocarbon polymer compound)

As can be seen in Fig. 4, mass wear $\mathrm{U}_{m}$ and linear wear $\mathrm{U}$ under fretting conditions are reduced several times by all types of coatings under study. Whereupon the fretting friction coefficient values obtained during tests do not correlate to the samples wear data. In the cases under consideration, friction coefficient is even higher than the one of the reference sample. 
This may be caused by both specific character of strain affecting friction joints under high standard loads under fretting conditions as compared to ordinary sliding friction and the nature of microstructural changes in surface layers of the joint parts. Besides, during model tests under actual loads and displacement amplitudes characteristic of operation conditions relatively small contact area of samples $\left(0,5 \mathrm{~cm}^{2}\right)$ brings about harder fretting conditions than in real joints. This also may increase friction coefficient several times as compared to sliding friction coefficient.

A raster electronic microscopic examination of friction surfaces has been carried out in order to detect the phenomena that reduce fretting wear when effective coatings are used.

Caverns filled with oxidized wear particles observed on friction surfaces of reference steel samples are typical of fretting wear. Oxidization is evidenced by a specific effect of electric charge accumulation on low-conductivity surface of oxidized particles that reduces image contrast and creates an impression of "fluorescence" under the impact of electron beam. Since such an effect is not observed on the rest of the friction surface, it is believed that wear particles were oxidized after they were formed as a result of interaction between oxygen and the surface of small particles that was activated in the process of friction. I.e. probably the process of corrosion is not related directly to the mechanics of fretting wear, moreover the areas with oxidized particles (Fig. 5, a) occupy a comparatively small part of the total friction area. Areas covered with particles several microns in size without oxidization traces (Fig. 5. b) are also encountered rather often on the 15 grade steel fretting wear tracks; brittle fracture cracks are clearly visible on them. Apparently, those particles are carbide or other inclusions characteristic of steel resulting from perlite interlayers fracture in the process of friction, etc.
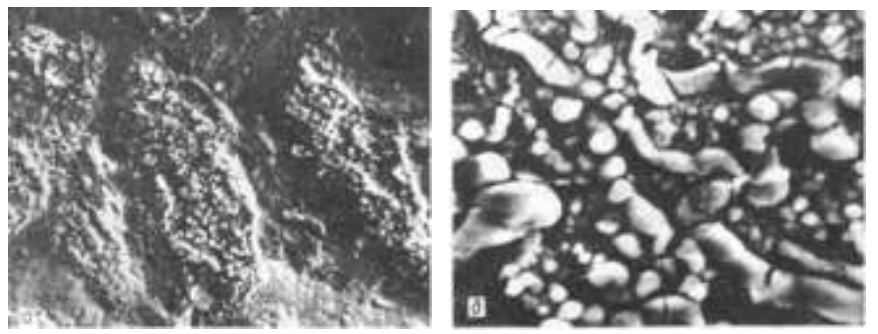

Fig. 5. Steel fretting wear surface: 5, a - caverns with wear particles, (x160); $5, \mathrm{~b}$ - particles on the friction surface, $(\mathrm{x} 2000)$

Application of fluorocarbon polymer compound solution with subsequent drying creates a thin polymer film on the surface. This film protects friction surfaces from oxidization and caving (Fig. 6), a) and somewhat increases the fineness of the particles visible on the surface, preventing their brittle fracture (Fig. 6, a as compared to Fig. 6, b).
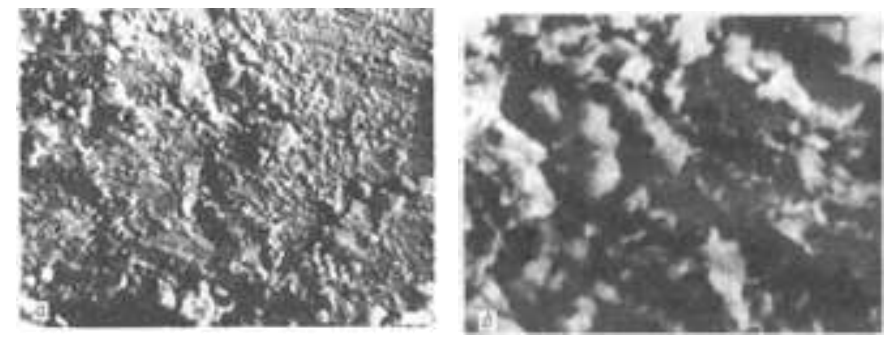

Fig. 6. Wear surface during fretting of fluorocarbon coated steel: $6, \mathrm{a}$ - a patch of friction surface, $(\mathrm{x} 200) ; 6, \mathrm{~b}$ - dispersed particles on the friction surface, (x2000)

In this case, microparticles, embedded in the polymer film created by the modifying agent, may probably act as a fine aggregate in the polymer matrix, forming a composite coating film. Composite polymer materials have shown themselves to advantage as antiwear and antifriction coatings. It is composite coating with a soft matrix and harder aggregate particles that reduce wear most efficiently; this phenomenon is implemented in the case under consideration as well.
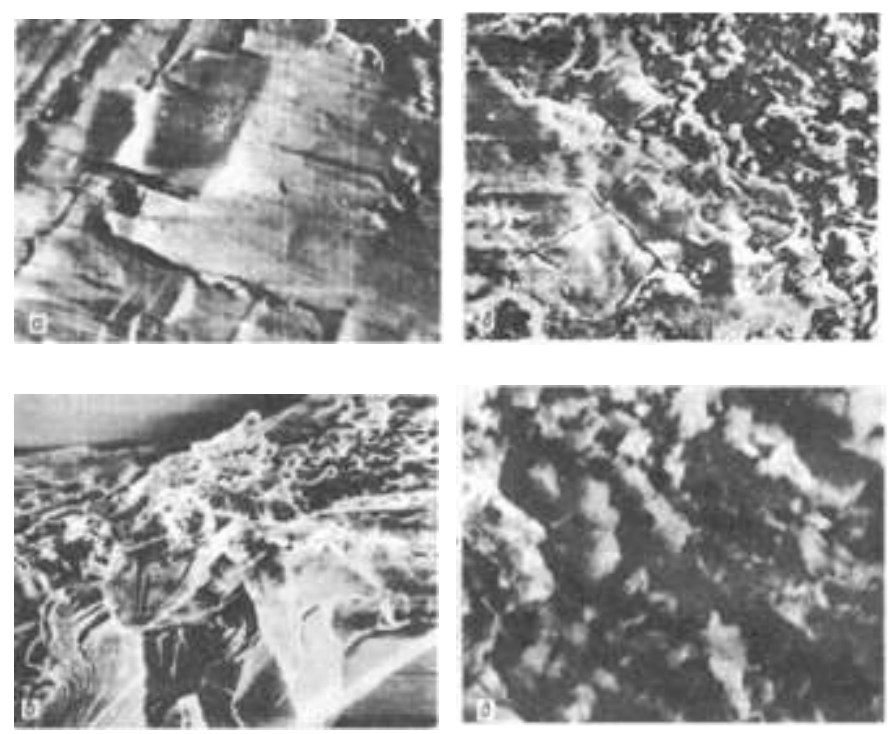

Fig. 7. Fretting wear surface (friction mechanical brass plated steel): 7,a - a layer of brass plating on the friction surface (x150); 7,b - alligatored brass plating after fretting (x300); 7,c - transverse fracture surface of a plated sample in liquid nitrogen - loose porous brass coating on coarse grain steel base (x400); 7,d - a fragment of low-temperature fracture of brass plating with a finely dispersed structure (x7000)

Friction surfaces of friction brass coated look somewhat differently. Brass plating creates very smooth layers of brass on the surface of a steel sample. Their adhesion to the surface is poor in some places; there they flake on the friction track during fretting (Fig. 7, a). But more frequently their adhesion is so good that even alligatoring does not bring about flaking and chipping of the brass coating (Fig. 7, b); this is probably the cause of its efficiency. In Fig. 7, c steel base grains are visible on the fracture surface; they are covered with a plastic, highly porous layer of brass several microns thick. One can see at high magnification that the structure of such layer 
consists of separate spherical particles approximately $1 \mu \mathrm{m}$ large and smaller (Fig. 7, d). Whereupon under the impact of high tensions and sliding velocities the highly dispersed structure of the layer created as a result of friction coating application ensure deformation under the impact of shear stress during fretting by means of mutual rotation and slipping of fine structural elements. Probably, this permits to deform thin subsurface layers of materials without dislocation causing fracture and wear. Implementation of such friction mechanics even at some areas of the contact surface may reduce total wear.

Comparative results of tests of vibration knurled and ground samples (in respect of mass and volume wear) after 500,000 cycles are shown in Fig. 8 (1, 2 - steel/steel couple; 3, 4 - cast iron/steel couple; 1, 3 - grinding, 2, 4 - vibration knurling). Vibration knurled samples have shown $30-35 \%$ less fretting wear resistance than the ground ones, after lubrication this difference mounts to $25 \ldots 30 \%[11,12]$.

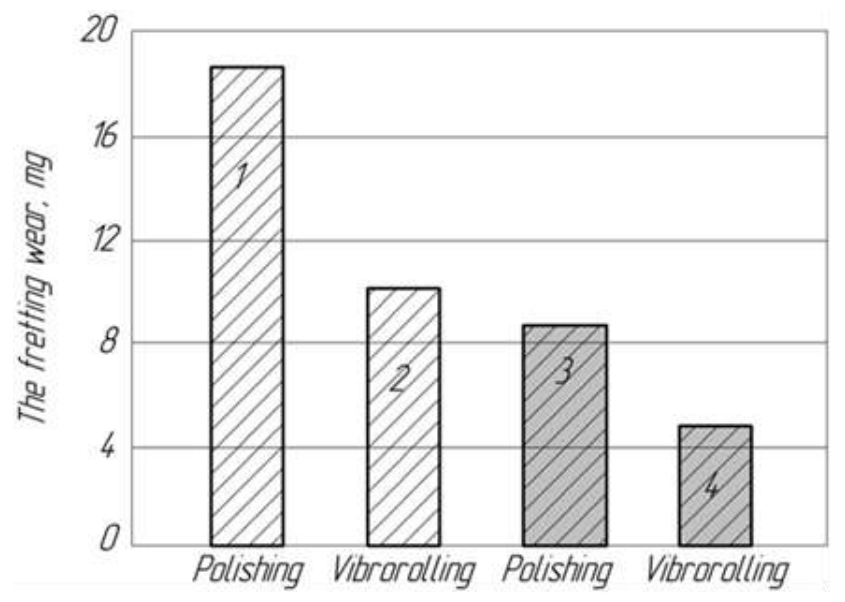

Fig. 8. Fretting wear dependence on processing type: 1,2 - steel samples and countersamples, 3, 4 - cast iron samples, steel countersamples; 1, 3 - after grinding, 2, 4 - after vibration knurling

Vibration knurled samples with a regular microrelief surface have a different wear resistance improvement mechanics. In Fig. 9,b, one can see that the friction track surface is broken down into separate facets whose dimensions are comparable with fretting displacement amplitude. No specific surface layers with a structure different from the original steel structure are visible within the borders of a single facet, except usual grooves in the sliding direction. Probably, such faceted nature of the friction tracks bears record to the process of splitting of strain and deformation waves on surfaces with a regular microrelief. This process contributes significantly to the fretting effects hardening.

Treatment, combining vibration knurling with application of thin-layer coatings that probably can reduce fretting wear even more, may be of interest for further studies.
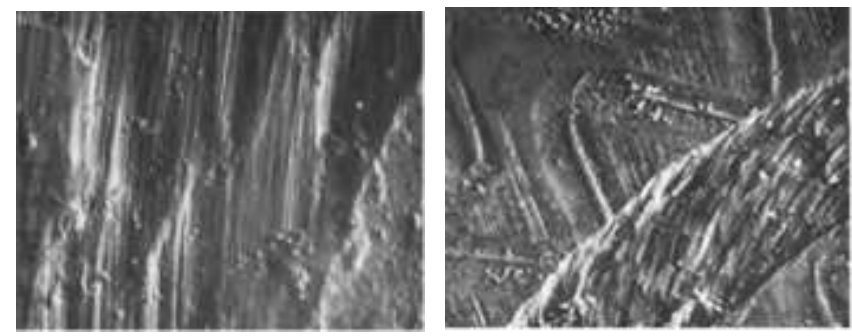

Fig. 9. Fretting friction track on steel surface: a) - grinding, b) - vibration knurling

\section{CONCLUSION}

(1) As a result of studies of heavily loaded joints of machine parts protection by fluorocarbon polymer compound, friction mechanical brass plating, it was established that such coatings have the same mechanics of fretting wear resistance improvement in the zone of contact layer of finely dispersed particles thanks to use of thin-layer coatings. The presence of such particles may be caused either by structural selforganization of the coating material in the process of friction brass plating, or by creation of a composite polymer coating with fine wear particles when a polymer compound is used. The protective coatings considered above virtually exclude the corrosion component of fretting wear.

(2) The dispersed structure of surface layers prevents implementation of the usual dislocation mechanics of strain hardening of surface layers of materials with their subsequent fracture when plasticity is exhausted as a result of dislocation in the slipping surfaces and the crack initiation process, leading to wear, which starts under the impact of dislocation accumulations. The size of dispersed particles (from fractions of a micron to several microns) is comparable with dislocations of free path length; therefore, they cannot cluster when they come to the borders of particles.

(3) In this case, nascence of discontinuities between structural elements leads to increased material porosity, but it is compensated by the process of structural accommodation during displacement of small particles. That is why there are no increased stress concentration and fracture on such pores. It is typical that even alligatoring wear resistant surfaces does not lead to their wear by flaking or chipping the surface layer and, possibly, but contributes to the improvement of dissipative properties of the surface. It may happen that the formation of such cracks may be caused not only by "rocking" of original material structural elements under the coating. Within the framework of synergic concepts of selforganization of structures in the process of friction, those cracks can be considered as boundaries of cells of a synergically dissipative structure.

(4) Studies of friction surfaces of samples, covered with thinlayer coatings, demonstrated that virtually in all cases, the reduction of wear during fretting tests is connected with presence of finely dispersed particles in the contact zone, allowing one to deform surface layers by mutual rotation and slipping of structural elements under the action of shear 
stresses without disintegration, causing surface wear. Perceptions of possible implementation of such "wearless" mechanics under friction permit one to approach more consciously to the choice of optimum materials for surface coating of friction parts and in case of fretting of heavily loaded joints of machine parts.

(5) Vibration knurling, forming a regular microrelief on friction surfaces open up significant opportunities for improving a number of performance characteristics of machine parts, primarily tribological ones. The effect of regular microrelief formation manifests itself most convincingly under severe sear conditions, preventing scoring, jamming and reducing fretting wear. The presence of a regular microrelief improves load-bearing capacity of surfaces, facilitates preservation of lubricant in the contact area and removal of wear products. Under fretting conditions, regular microrelief facilitates splitting strain and deformation waves on the surface, improving shear sensitivity and preventing fatigue damage development. Under fretting corrosion conditions, the method of vibration knurling, forming a regular microrelief, is able to compete with traditional coating application methods (electroplating, deposition, etc.). The combination of vibration knurling with application of thinlayer coatings, capable of reducing fretting wear to an even greater extent without reducing specified negative allowances, looks very promising.

\section{References}

[1] M. S. Ostrovskiy, «Fretting as a cause of reduced reliability of mining machines», Mining information-analytical Bulletin, vol. 3, №. 12, pp. 315-331, 2011.

[2] R. B Waterhouse, Fretting-corrosion, Leningrad, Mechanical engineering, 1976, $272 \mathrm{p}$.

[3] D. N. Garkunov, Tribology, Moscow, KNORUS, 2013, 408 p.

[4] A. V. Gilev, Basic maintenance of mining machines and equipment, Krasnoyarsk, Sib. Feder. Univ., 2011, 276 p.

[5] Yu. N. Drozdov, Applied tribology (friction, wear and lubrication) Moscow, Eco-Press, 2010, 604 p.

[6] W. Zhang, Q. Xue, «Fretting wear characteristics of $\mathrm{Ni} / \mathrm{Cu}$ multilayers electrodeposited on beryllium bronze substrate», Wear, vol. 214, pp. 2329, 1998.

[7] I. R. Aslanyan, J. P. Selis and L. Sh. Shuster, «Fretting-corrosion of electrolytic NiP coatings», Friction and wear, №. 6, vol. 32, pp. 556561, 2011.

[8] M. Varenberg, G. Halperin and I. Etsion, «Different aspects of the role of wear debris in fretting wear», Wear, № 11-12, vol. 252, pp. 902910, 2002.

[9] A.Volchok, «The effect of surface regular microtopography on fretting fatigue life», Wear, № 3-4, vol. 253, pp. 509-515, 2002.

[10] V. Krasnyy, V. Maksarov and J. Olt, «Improving fretting resistance of heavily loaded friction machine parts using a modified polymer composition», Agronomy Research, vol. 14(S1), pp.1023-1033, 2016.

[11] Y. G. Schneider, Operational details properties with regular microrelief, Leningrad, Engineering, 1982, 248 p.

[12] V. Krasnyy, V. Maksarov and J. Olt, «Increase of wear and fretting resistance of mining machinery parts with regular roughness patterns», Annals of DAAAM and Proceedings of the International DAAAM Symposium, pp. 151-156, October, 2016 [27TH DAAAM INTERNATIONAL SYMPOSIUM ON INTELLIGENT MANUFACTURING AND AUTOMATION, 2016], DOI: 10.2507/27th.daaam.proceedings.023. 